\title{
Nurses' Preparedness for Disaster in South Khorasan Province, Iran
}

\author{
Shahnaz Tabiee ${ }^{1}$, Maryam Nakhaei ${ }^{{ }^{*}}$
}

1. Department of Nursing, Faculty of Nursing \& Midwifery, Birjand University of Medical Sciences, Birjand, Iran

Cttation: Tabiee Sh, Nakhaei M. Nurses' Preparedness for Disaster in South Khorasan Province, Iran. Health in Emergencies \& Disasters Quarterly. 2016; 2(1):13-18. https://doi.org/10.18869/nrip.hdq.2.1.13

https://doi.org/10.18869/nrip.hdq.2.1.13

Article info:

Received: 03 May 2016

Accepted: 16 Aug. 2016

\section{Keywords:}

Emergency preparedness, Nurses, Disaster

\begin{abstract}
Background: Nurses, as the largest group in providing relief during disasters with their specialized skills, should be sufficiently prepared to provide the highest level of health care. By compiling predisaster preparedness programs, the provided healthcare would be promoted and number of casualties and incoordination in allocated tasks be reduced. This study was conducted to evaluate nurses' preparedness in response to disasters in South Khorasan Province, Iran.
\end{abstract}

Materials and Methods: In this correlational descriptive study, working nurses in provincial hospitals were chosen by systematic random sampling. The study data were collected with a 3-part questionnaire: demographic information, items assessing the capabilities in disaster (clinical competency, survival skills, operational competency), and items regarding their viewpoints (personal and psychological readiness, team integration, and administrative support). The questionnaire was rated on a 5-point Likert-type scale. Total score in each field is divided by the number of questions, in which 5 is the highest, and 1 the lowest. All data were analyzed by SPSS16. The significant level was set at $\mathrm{P} \leq 0.05$.

Results: Out of 304 hospital nurses working in 10 health centers throughout the province, $71.1 \%$ were female, $27.21 \%$ had 3-5 years of job experience, $96.4 \%$ had BS in nursing, and $57.9 \%$ were the staff of educational hospitals. The mean (SD) score for nurses' preparedness (competency and attitude) was 3.4(0.64). The mean (SD) score for nurses' competency was 3.25 (0.72), and average score for nurses' attitude was 3.53(0.5). There was a significant correlation between nurses' competency score and their gender and work experience $(\mathrm{P} \leq 0.05)$.

Conclusion: Regarding the nurses' preparedness score, it is recommended that they be provided with training courses on disaster preparedness through workshops and or training exercises.

\section{Introduction}

ince the dawn of history, disasters have always been a part of man's life resulting in early death, disturbing the life quality and health, and displacement [1]. Disasters are a series of physical, social, economic, and political incidents which normally do not follow definite patterns and boundaries [2]. During disasters, the capacity of using physical and

* Corresponding Author:

Maryam Nakhaei, PhD

Address: Department of Nursing, Faculty of Nursing \& Midwifery, Birjand University of Medical Sciences, Birjand, Iran.

E-mail: maryamnakhaee.mn@gmail.com 
human resources and implementing effective preparedness and response strategies increase [3].

The current statistics indicate an increase in incidents and disasters and insufficient preparedness to respond [4$6]$. Since disasters influence health and well-being of the society, delivering proper health services is considered as the major component in surviving, reducing causalities, and providing the people with suitable welfare after such incidents [7]. The most effective way of responding to the emerging needs at this time is preparedness, which is considered as a long-lasting concern by WHO. This organization defines preparedness as a part of the sustainable development of societies and emphasizes the importance of most needed activities to achieve preparedness [8].

Nurses are the largest group in providing healthcare services and have critical roles in confronting the disasters, providing services as the first responders, conducting triage, coordinating, and also training and giving consultation to those giving services [9]. Therefore, these people must be professionally prepared [5].

The International Council of Nurses with regard to the importance of the nurses' presence in disasters, states 'Nurses with their technical skills and scientific knowledge can collaborate in disaster preparedness programs and during incidents. They play a strategic role as the members of caring team in collaborating with other groups and organizations." [10].

Previous studies show that nurses are not sufficiently educated and prepared for such tasks. The study by Ghanbari et al. showed that $80.7 \%$ of nurses are not trained for such situations [6]. The studies in Hong Kong [11], Jordan [4], Singapore [12], and Egypt [9] have also reported nurses' insufficient preparedness in disasters. Dolatabadi et al. mentioned insufficient knowledge and unpreparedness as the causes of emotional stresses meddling with nurses' tasks in such situations; they believed that nurses' preparedness for responding in disasters helped them to boost their confidence, and reduce the loses and vulnerabilities in confronting with unpredictable incidents [13]. Also, WHO indicates that preparing and educating staffs are the effective elements on decreasing damages of such disasters [8]. Khanekeh et al. introduced trained forces as facilitators in providing healthcare in disasters [14]. Since the routine healthcare in the community gets disturbed because of emergent and complex situations or in large scale disasters, nurses should use their unique skills and competence and have sufficiently prepared to provide the highest level of care [15]. It has been proven that in those societies, which have already developed predisaster preparedness programs, causalities and inco- ordination in the assigned duties reduces significantly; however, changing the existing behaviors, which are fully based on recovery relief and aid, needs predisaster preventions that entail specific management, public training, and collaboration [16].

The conducted studies in this field indicate the necessity for attention to preparedness of nurses. However, planning in this area needs awareness of the present situation and its strong and weak points. Thus regarding the few studies conducted in the field of nurses' responses in disasters, this research was designed to determine the preparedness of nurses in South Khorasan Province in response to disasters.

\section{Materials and Methods}

In this descriptive-analytical study, 304 nurses working in different hospitals in South Khorasan cities (Imam Reza Educational Hospital, Vali-ye Asr Educational Hospital, Social Security Hospital, Shohada Qaen Hospital, Shahid Chamran Hospital in Ferdows and Sarayan, Shahid Mostafa Khomeini Hospital in Tabas, Shafa Hospital in Boshrouye; Shahid Atash-Dast Hospital in Nehbandan, and Sarbishe Hospital) were chosen by systematic random sampling method. Sample size was estimated 152 according to Ghanbari et al. study [4] and the formula: $\mathrm{n}=(\mathrm{z} 1-\alpha \div 2) 2 \times \mathrm{s} 2 \div \mathrm{d} 2$, which became double to get better precision in results.

Data collection tool was Readiness Estimate and Deployability Index (READI). The index has three parts. The first part includes 18 items about demographic information (age, gender, marital status, workplace, educational background in triage, response to disasters, and so on). The second part has 27 statements about competency in response to disasters in three fields; clinical competency (19 statements), survival skills (3 statements), and operational competency ( 5 statements) rated on a 5-point scale (1. I need more education, presentation, and exercise under supervision; 2 . I need to review and exercise under limited supervision; 3. I need to review and limited supervision; 4. I just need to review; and 5. I neither need review nor supervision) with the highest score of 135 points. The third part of the questionnaire includes 32 statements about the nurses' attitudes on disaster preparedness in the fields of psychological readiness (7 statements with 5 choices from completely prepared to I don't know), personal readiness (8 statements), group integration (10 statements), and administrative support (7 statements with 5-point scale from completely disagree:1, to completely agree: 5) with the highest score of 160 [17].

Preparedness is measured in this study by considering total score in the fields of competencies and attitudes. In each 
field (competency, attitude), the total score was divided by the number of questions, in which 5 is regarded as the highest score, and 1 the lowest score. The questionnaire was used by Morris (2002), and its validity in different fields was reported from 0.88 to 0.96 [17]. This validity is reported from 0.69 to 0.83 by Rivers et al. [18]. The questionnaire after translation was approved by 5 faculties of Nursing and Midwifery, and Emergency Medicine specialists; and its reliability was confirmed after filling out by 20 nurses and calculating its Cronbach $\alpha$ coefficient $(\alpha=0.91)$.

SPSS (version 15) was used to analyze the collected data through parametric/ nonparametric statistical tests at significant level of $\mathrm{P}<0.05$. The obtained data were first checked for normal distribution by KolmogorovSmirnov test. Then, due to being normally distributed, the Independent $t$ test and 1-way analysis of variance were used to analyze the data.

\section{Results}

In this study, 304 working nurses in 9 hospitals and healthcare centers in South Khorasan Province participated. A total of $216(71.1 \%)$ of them were females, 184 $(60.5 \%)$ aged between 25 and 35 years, $86(28.3 \%)$ had 3 to 5 years job experience, $293(96.4 \%)$ had BS in nursing, and $176(57.9 \%)$ were working in educational hospitals.

A total of 147 (48.4\%) nurses reported confronting with some disasters, including car accidents (51.7\%), and earthquakes (44.3\%). Also, 205 (67.4\%) nurses had passed disaster training course, $114(37.5 \%)$ had taken part in theoretical courses, and just $71(23.23 \%)$ in exercises. However, 282 (92.8\%) nurses expressed their need to further studies and $117(38.5 \%)$ had had triage education just during their undergraduate courses.

Nurses' preparedness average (SD) score (competency and attitude) was $3.4(0.46)$ out of 5 . Their average (SD) score for competency was $3.25(0.72)$ and for attitude as $3.53(0.5)$ (Table 1).

With regard to competency, and also the component of clinical competency, the men's score $(3.46 \pm 0.55)$ was higher than women's $(\mathrm{P}=0.008)$, but there were no significant relationships between gender and general preparedness or attitude $(\mathrm{P}>0.05)$. In this regard, the average score of those having job experience for more than 10 years $(3.47 \pm 0.54)$ was higher than those with shorter job experience $(\mathrm{P}=0.000)$. General preparedness score was also higher for nurses with more than 10 years job experience $(3.5 \pm 0.42)(\mathrm{P}=0.009)$. There were no significant relationships between the ward working or the hospital (educational or non-educational) and the preparedness and its dimensions $(\mathrm{P}>0.05)$. With regard to the attitude, the score of those confronting some cases of disaster was higher $(3.59 \pm 0.45)(\mathrm{P}=0.02)$, but no significant difference was seen in the scores of competency and general preparedness $(\mathrm{P}>0.05)$. Those trained for disasters had higher scores in general preparedness $(3.44 \pm 0.48)(\mathrm{P}=0.03)$.

Table 1. The average score of nurses' preparedness in responding to disasters in the areas of competency and attitude

\begin{tabular}{|c|c|c|}
\hline Dimension & Component & Mean \pm SD \\
\hline \multirow{5}{*}{ Competency } & Clinical competency & $3.35 \pm 0.82$ \\
\hline & Survival skills & $3.31 \pm 0.95$ \\
\hline & & \\
\hline & Operational competency & $2.98 \pm 0.88$ \\
\hline & General competency & $3.25 \pm 0.72$ \\
\hline \multirow{5}{*}{ Attitude } & Psychological preparedness & $3.48 \pm 0.69$ \\
\hline & Personal preparedness & $3.5 \pm 0.62$ \\
\hline & Team integration & $3.63 \pm 0.57$ \\
\hline & Administrative support & $3.46 \pm 0.92$ \\
\hline & General attitude & $3.53 \pm 0.5$ \\
\hline Preparedness & $\ldots \ldots \ldots$ & $3.4 \pm 0.46$ \\
\hline
\end{tabular}


Within group analysis of variance for the relationship among different components in this area showed that in the area of competency, nurses' mean score of clinical competency $(3.35 \pm 0.82)$ was higher than operational competency $(2.98 \pm 0.88)(\mathrm{P}<0.001)$, but the difference was not significant in other components.

In the field of attitude, the average score of nurses' team integration $(3.63 \pm 0.57)$ was higher than other components in this area $(\mathrm{P}<0.001)$.

\section{Discussion}

This paper aimed to study the South Khorasan nurses' preparedness in responding to disasters. The nurses' preparedness average (SD) score was $3.4(0.46)$ out of 5 , which was estimated as moderate. Nurses' average score was also found moderate in the studies by Oztekin (2016) in Japan, and Chi Tzeng (2016) in Taiwan [19, 20]. Nurses' average score is also found weak in the studies conducted in USA, Australia, Hong Kong, and Egypt [9, 11, 18, 21, 22]. This difference might be attributed to study topics, setting and regional conditions, the type of hospital, and the way to develop and implement educational programs in relation to disaster preparedness. However, the findings suggest that nurses are not fully prepared to respond the disasters; it is therefore necessary to recognize the weak and strong points in different areas and phases of preparedness and responding and develop and implement appropriate methods and high quality training programs.

The average (SD) score of competency was $3.25(0.72)$ out of 5 in this study, which was evaluated as moderate. In this field, the average score of clinical competency was higher than other components $(\mathrm{P}=0.001)$. The nurses' average score in this area was reported poor by Rivers (2006), yet the score of clinical competency was higher than the other components $(\mathrm{P}=0.01)$ [18]. Chi Tzeng (2016) also reported that Taiwanese nurses had the highest average score for preparedness in the area of clinical competences $(\mathrm{P}<0.05)$ [20]. The average score for Japanese nurses was higher in the area of clinical competency compared to other areas $(\mathrm{P}<0.001)$ [19].

Regarding the relation between demographic characteristics and research variables in this study, the average score of competency, and the component of clinical competency in male nurses, and those with more than 10 years job experience were higher $(\mathrm{P}<0.001)$. The average score of clinical competency showed significant relationship to age, education, and job experience in Japanese nurses ( $\mathrm{P}$ $<0.05$ ) [19]. In Taiwanese nurses, the average score of clinical competency showed relationship with education, job experience for more than 10 years, and working in the ICU and emergency rooms $(\mathrm{P}<0.001)$ [20].

Studies show that job experience influences the clinical competency. However, the average score of nurses' competency in survival skills and also operational competency are poor in this area, both in our study, as well as some others [11, 18-20]. The nurses are not suitably prepared with regard to patients' discharge, operating the required equipment outside the hospitals, using disinfection and personal protection equipment, wearing protective covers, and relevant care in biological and chemical attacks, utilizing communication tools, and even identifying secure places in the geographical region of their duty. This issue could affect the nursing care planning, coordinating care team, and finally delivering fast and on time services [23].

Most nurses in our study (92.8\%) mentioned the need for continuous training. The average score of preparedness in Jordan study (2012) for the nurses working in educational hospitals was more than those in public ones $(\mathrm{P}=0.001)$ [4], which was not significant in our study. In the event of a disaster, nurses regardless of their location, are among the first groups speeding to give services. Though they are potentially qualified for the situation, they should participate in training courses and exercises to realize their readiness [24].

With regard to attitude, in our study, the nurses' average (SD) score was $3.53(0.5)$ at moderate level. The average score in this area for those nurses with experience in crisis was higher $(\mathrm{P}=0.02)$. The Taiwan study (2016) showed a similar result; the Taiwanese nurses' average score in this area showed relationship with their education, job experience in ICU and emergency rooms, as well as participating in training courses related to disasters ( $\mathrm{P}<0.001)$ [20]. Rivers study (2006) reports the nurses' average score in this area as moderate, though the score was higher for those nurses working in trauma center hospitals [18].

\section{Conclusion}

The results from relevant studies show that nurses who were in real or simulated disaster situations have better understanding about competency development and strengthening their disasters preparedness and develop more tendency and self-confidence in responding to the incidents and disasters [20]. Nurses are called to the scenes for giving services to those injured and in need of care as the first responders; therefore they have to know 
how to overcome the disaster problems by using ordered strategies, and deliver efficient responses to the incidents and disasters by being aware of their various roles [10].

Practical knowledge and technical skills that are considered as the worthiness of a nurse in such a situation requires using such capabilities as critical thinking, adaptability, team work, and leadership. Caring for the patients and proper management in such situations need a true understanding of individual and group care. Nurses should be aware that when the society needs healthcare services, they should be fully prepared to give services $[10,25]$.

It seems essential for the nursing directors to engage the nurses and use their ideas in planning for crisis. It is also possible to strengthen the power of the nurses in disasters by planning and implementing the retraining programs, executing staff rotation shifts in ICU and emergency rooms, and also supporting nurses to promote their capabilities in response to disasters [5]. It is also necessary to insist on disasters nursing cares in the training courses of the nurses, and by using educational proper strategies such as exercises and simulating the crisis situations, promote the nurses' preparedness to response in disasters [11].

\section{Acknowledgements}

This study was supported by East Nursing \& Midwifery Research Center, Birjand University of Medical Sciences (BUMS) in Iran. The authors wish to thank all participants for their support and involvement in this study.

\section{Conflict of Interest}

The authors declared no conflict of interests.

\section{References}

[1] Veenemw TG. Disaster nursing and emergency preparedness for chemical, biological and radiology terrorism and other hazards. $3^{\text {rd }}$ ed. New York: Springer; 2013.

[2] Rokkas P. Steenkamp M. Disaster preparedness and response: Challenges for Australian public health nurses: A literature review. Nursing and Health Sciences. 2014; 16(1):6066. doi: $10.1111 /$ nhs.12134

[3] Barna S. Goodman B. Mortimer F. The health effects of climate change: What does a nurse need to know? Nurse Education Today. 2011; 32(7):765-771. doi: 10.1016/j. nedt.2012.05.012
[4] Alkhalaileh MA. Bond E. Alasad JA. Jordanian nurses perceptions of their preparedness for disaster management International Emergency Nursing. 2012; 20(1):14-23. doi: 10.1016/j.ienj.2011.01.001

[5] Pesiridis T, Sourtzi P, Galanis P, Kalokairinous A. Development, implementation and evaluation of a disaster training program for nurses: A switching replication randomized controlled trial. Nurse Education in Practice. 2015; 15(1):63-67. doi: 10.1016/j.nepr.2014.02.001

[6] Khankeh HR, Mohammadi R, Ahmadi F. [Healthcare services at time of natural disasters: A qualitative study (Persian)] Iran Journal of Nursing. 2007; 20(31):84-96.

[7] Ghanbari V, Madah B, Khankeh HR, Karimloo M, Ardalan A. [The effect of a disaster nursing education program on nurses' preparedness for responding to probable natural disasters (Persian)]. Iran Journal of Nursing. 2011; 24(73):72-80.

[8] World Health Organization. Risk reduction and emergency preparedness: WHO six year strategy sector and capacity development. Geneva: World Health Organization; 2009.

[9] Diab GM, Mabrouk SM. The effect of guidance booklet on knowledge and attitudes of nurses regarding disaster preparedness at hospitals. Journal of Nursing Education and Practice. 2015; 5(9):17- 31. doi: 10.5430/jnep.v5n9p17

[10] Powers R, Daily E. International disaster nursing. Cambridge: Cambridge University Press; 2010.

[11] Yuen Loke A, Wai ManFung O. Nurses' competencies in disaster nursing: Implications for curriculum development and public health. Public Health; 2014; 11(3):3289-3303. doi: 10.3390/ijerph110303289

[12] Wee FC. (P2-57) Nurses' knowledge, skills and perception towards disaster response and emergency preparedness. PreHospital and Disaster Medicine. 2011; 26(1):162. doi: 10.1017/ s1049023x11005000

[13] Abbasi Dolatabadi Z, Delkhosh M, Abbasian F, Soltaninejad S, Abdi Gangabadi MR, Saeedi S. [Nurses' need for vigilance in disaster response (Persian)]. Paper presented at: The 5th Seminar on Nurses, Midwives, and Research; 2012 Dec 7-8; Tehran, Iran.

[14] Khankeh H, Mohammadi R, Ahmadi F. [Barrier and facilitators of healthcare services at the time of natural disaster (Persian)]. Journal of Rehabilitation. 2005; 6(1):23-30.

[15] Saghafinia M, Daniel Z, Ghomian Z, Haeri AA. [Effects of educational pamphelets of disasters dealing on increasing individuals awaredness (Persian)]. Journal of Military Medicine.2009; 11(3):161-4.

[16] Abaszadeh MM, Nikbakht Nasrabadi A, Vaskoui Eshkevari Kh. [Assessing educational needs of nurse managers affiliated to state hospitals (Persian)]. Iranian Journal of Nursing Research. 2010; 4(15):16-24.

[17] Morris MK. A readiness evaluation of professional filler system and forces command nurses at Darnell army community hospital, fort hood, Texas. New York: National Technical Reports Library; 2002.

[18] Rivers F, Wertenberger DH. U.S. army professional filler system nursing personnel: Do they possess competency needed for deployment? Military Medicine. 2006; 171(2):142-149. doi: 10.7205/milmed.171.2.142 
[19] Oztekin SD, Larson EE, Akahoshi M, Oztekin I. Japanese nurses' perception of their preparedness for disasters: Quantitative survey research on one prefecture in Japan. Japan Journal of Nursing Science. 2016; 13(3):391-401. doi: 10.1111/ jins.12121

[20] Chi Tzeng W, Pei Feng H, Tung Cheng W, Huei Lin C, Chi Chiang L, Pai L, et al. Readiness of hospital nurses for disaster responses in Taiwan: A cross-sectional study. Nurse Education Today. 2016; 47:37-42. doi: 10.1016/j.nedt2016.02.025

[21] Corrigan, E, Samrasinghe, I, 2012. Disaster preparedness in an Australian urban trauma center: Staff knowledge and perceptions. Pre-Hospital \& Disaster Medicine. 27(5):432-438. doi: 10.1017/S1049023X12001045

[22] Baack S, Alfred D. Nurses' preparedness and perceived competence in managing disasters. Journal of Nursing Scholarship. 2013; 45(3):281-287. doi: 10.1111/jnu.12029

[23] Zarea K, Beiranvand S, Sheini-Jaberi P, Nikbakht-Nasrabadi A. Disaster nursing in Iran: Challenges and opportunities. Australasian Emergency Nursing Journal. 2014; 17(4):190196. doi: 10.1016/j.aenj.2014.05.006

[24] Low LP, Hummel FI. Disaster readiness for nurses in the workplace. Workplace Health \& Safety. 2014; 62(5):207-213. doi: $10.1177 / 216507991406200505$

[25] Wenji ZH, Turale S, Stone TE, Petrini MA. Chinese nurses' relief experiences following two earthquakes: Implications for disaster education and policy development. Nurse Education in Practice. 2015; 15(1):75-81. doi: 10.1016/j.nepr.2014.06.011 